\title{
INCLUSÃO DE ALUNOS COM DEFICIÊNCIA NOS ANOS INICIAIS DO ENSINO FUNDAMENTAL: ALGUMAS CONSIDERAÇÕES
}

\author{
Elizabeth Regina Streisky de FARIAS ${ }^{1}$ \\ Gilmar de Carvalho CRUZ ${ }^{2}$ \\ Marta Burda SCHASTAI ${ }^{3}$
}

RESUMO: O presente texto visa discutir, mesmo que de uma forma breve, a inclusão na escola regular de alunos com deficiência. Para isto, buscou-se uma fundamentação baseada, na análise de documentos legais que tratam da política pública da inclusão escolar de alunos com deficiência no Brasil, bem como em autores que tratam da temática. O texto trata ainda do processo de ensino e aprendizagem, bem como do fracasso escolar, considerando o cotidiano escolar, o estilo de gestão escolar e as práticas pedagógicas presentes na escola pública, como categorias relevantes no processo de inclusão escolar de alunos com deficiência.

PALAVRAS-CHAVE: Inclusão. Políticas públicas. Alunos com deficiência.

\section{Introdução}

Eu sei muito pouco. Mas tenho a meu favor tudo o que eu não sei por ser um campo virgem - está livre de preconceitos. Tudo o que não sei é minha parte maior e melhor: é a minha largueza. É com ela que eu compreenderia tudo. Tudo que não sei é que constitui a minha verdade.

Clarice Lispector (1984, p.461)

Recentemente, o contexto educacional e político no Brasil viram-se invadidos pela discussão quanto à inclusão de pessoas com deficiência na escola regular ${ }^{4}$. A

\footnotetext{
1 Doutoranda em Educação. UEPG - Universidade Estadual de Ponta Grossa. Programa de PósGraduação em Educação. Ponta Grossa - PR - Brasil. 84030-900 - bety.farias@ bol.com.br.

${ }^{2}$ Professor Associado. UEPG - Universidade Estadual de Ponta Grossa. Programa de Pós-Graduação em Educação. Ponta Grossa - PR - Brasil. 84030-900. UNICENTRO - Universidade Estadual do CentroOeste. Guarapuava - PR - Brasil. 85015-430 - gilmailcruz@ gmail.com.

${ }^{3}$ Doutoranda em Educação Matemática. UEL - Universidade Estadual de Londrina. Programa de PósGraduação em Ensino de Ciências e Educação Matemática. Londrina - PR - Brasil. 86057-970 martaschastai@gmail.com.

4 Neste texto os termo escola "comum" e "ensino regular" aparecem como sinônimos, entretanto como lembram Glat e Blanco (2007), as escolas especiais - desde que autorizadas pelos órgãos normativos dos sistemas de ensino - são instituições regulares.
} 
finalidade de tal discussão é assegurar a todos os mesmos direitos quanto ao acesso e à aprendizagem em espaços escolares, em condições menos restritivas possíveis.

Embora os marcos legais assegurem a inclusão de todos no espaço escolar, sabese que a aprendizagem nem sempre se efetiva, já que a escola tem fracassado na tarefa de assegurar a aprendizagem até mesmo dos alunos ditos "normais". Neste sentido, não se trata somente de assegurar a aprovação, melhorando com isto os índices estatísticos, mas garantir a aprendizagem.

Nesta perspectiva Charlot (2005), afirma que não existe fracasso escolar, o que existe são alunos que apresentam dificuldades para aprender. $\mathrm{O}$ mesmo autor indica ainda que o suposto fracasso apresentado pela escola é na maioria das vezes atribuído às classes populares, sem levar em consideração as formas de organização e gestão da escola e a forma como se dá o processo ensino e aprendizagem.

Compreende-se também que a escola não alterou suas práticas cotidianas, permanecendo excludente e dualista, já que historicamente tem classificado os alunos em bons e maus dependendo de seu desempenho escolar. Para isto são utilizados instrumentos avaliativos que se limitam a quantificar os resultados do desempenho escolar expressos em notas ou conceito escolares.

Pode-se dizer que a avaliação escolar exerce papel relevante na questão do sucesso ou insucesso do educando, porém permanecem restritas ao desempenho do aluno, sem considerar a forma de organização escolar, as práticas pedagógicas e o estágio de compreensão que o aluno se encontra.

Desta forma, a avaliação está restrita ao ponto de chegada, não servindo como ponto de partida para reflexão e busca de novas práticas.

Neste sentido, Paro chama a atenção, dizendo que

[...] a razão de ser da avaliação educativa não é classificação ou a retenção de alunos, mas a identificação do estágio de compreensão e assimilação do saber pelo educando, junto com as dificuldades que este encontra, bem como os fatores que determinam tais dificuldades, com vistas à adoção de medidas corretivas da ação. (PARO, 2001, p.39-40).

É preciso reconhecer o espaço escolar como espaço social, no qual os atores sociais dão vida e significado ao estabelecido por lei. Neste contexto, tais atores produzem uma cultura organizacional própria, uma prática pedagógica singular, muitas vezes oculta a um olhar menos atento. 
Considera-se que a escola pública ainda é palco de limitações acentuadas. Limitações estas que estão expressas nas barreiras arquitetônicas que impedem o acesso de todas as pessoas ao ambiente escolar, bem como nas barreiras pedagógicas, que impedem o aprendizado. Ambas estão ligadas a opções quanto à política educacional do município/estado, ao estilo de gestão adotado pela escola e a formação inicial e continuada do professor.

A inclusão pressupõe uma ideia de composição de um todo e o enriquecimento pela diversidade. Nesta perspectiva, propõe um novo arranjo pedagógico: diferentes estratégias de ensino, flexibilização curricular, práticas avaliativas coerentes e modificações na sua organização de espaços e tempos escolares, ou seja, uma escola flexível, dinâmica, que vise atender as diferenças individuais.

Neste contexto, o presente texto pretende contribuir na discussão quanto à inclusão no espaço da escola pública regular, indicando possibilidades e desafios na efetivação da mesma.

\section{Educação inclusiva: um novo caminho?}

Nos primórdios da humanidade somente os mais fortes sobreviviam, qualquer diversidade humana era encarada como uma aberração e estas pessoas que fugiam dos padrões ditados pela sociedade, eram excluídas do convívio social.

Recentemente com o desenvolvimento cultural, científico, econômico e tecnológico, as necessidades de sobrevivência foram mudando e as pessoas que não se enquadravam na normalidade passaram a ganhar condições mais dignas de sobrevivência.

Nesta perspectiva, a educação da pessoa com deficiência era baseada em um modelo clínico, sendo que esta era vista como inválida e incapaz, que pouco poderia contribuir com a sociedade, devendo ficar segregada somente aos cuidados das famílias e profissionais, não tendo o direito ao contato com demais pessoas da sociedade.

A partir da segunda metade do século XX, principalmente com o desenvolvimento de estudos relacionados à medicina e à saúde começaram a surgir propostas educacionais alternativas de atendimento a essa população antes excluída.

Os encontros internacionais, com destaque para Jomtien (WCEFA, 1990) e Salamanca (Espanha, 1994), representam um marco nas discussões acerca do direito ao acesso e permanência na escola para os alunos com deficiência. 
Já no Brasil, a Educação Especial se institucionalizou em termos de planejamento de políticas públicas com a criação do CENESP (Centro Nacional de Educação Especial) em 1973, começando então a criação de escolas especiais e implantação de classes especiais nas escolas públicas de regulares. Em 1986, o CENESP transformou-se em SEESP (Secretaria de Educação Especial) e isso permitiu o desenvolvimento acadêmico de docentes na área de educação especial. Em 2011 esta mesma secretaria passa a denominar-se SECADI (Secretaria de Educação Continuada, Alfabetização, Diversidade e Inclusão), abrangendo assim a inclusão como um todo, porém contemplando a educação especial como um dos eixos de trabalho da mesma.

É importante ressaltar que a proposta da Educação Inclusiva, como explicitada na Declaração de Salamanca e em outras diretrizes, não remete exclusivamente às pessoas com deficiência ou condições atípicas. Abrange, sim, todos os grupos excluídos do processo formal de escolarização. Seu pressuposto é de que não são os alunos quem devem adaptar-se as condições da escola, mas a escola é que deve adaptar-se para atender a todos os alunos, independentemente de suas condições físicas, intelectuais, sociais, emocionais, linguísticas, entre outras.

É fato que o discurso da Declaração de Salamanca a respeito da Educação Inclusiva, é realmente algo muito humano e até tocante quando ressalta que todas as pessoas, independente de suas limitações, têm direitos iguais, inclusive de convivência escolar. Entretanto, é importante deixar claro que a escola, antes de qualquer função social, tem um papel pedagógico de desenvolvimento cognitivo. Ou seja, fazer ou colocar em prática a ideia da Educação Inclusiva conforme referida nos documentos citados anteriormente, requer, por parte de todos os envolvidos, um grande compromisso em prol da qualidade dessa educação.

Diante do exposto, pode-se afirmar que a Educação Inclusiva pode ser considerada um novo paradigma educacional, considerando também que o fracasso escolar não é simplesmente uma consequência das deficiências ou problemas intrínsecos dos alunos, mas sim, resultado de variáveis inerentes ao próprio sistema escolar.

No Brasil, as modificações previstas nos marcos legais - anteriores à declaração de Jomtien - estão expressas na Lei 4024/61 (BRASIL, 1961) que estabelece as diretrizes para a educação nacional. Neste texto, começa a despontar a possibilidade de inserção do aluno com deficiência no ensino comum, porém, ainda, com um caráter segregativo conforme explicita o artigo 88: “a educação de excepcionais deve, no que 
for possível, enquadrar-se no sistema geral da educação, a fim de integrá-los no sistema comum de educação".

Batista (2003, p.17), chama a atenção para as desvantagens decorrentes desta ação:

\begin{abstract}
Estar separado do convívio social em nome de um tratamento ou atendimento especializado, significou para as pessoas com deficiência, estarem em organizações especializadas ou escolas especiais e não terem acesso aos meios de educação ou oportunidades de acesso ao trabalho que são comuns as demais pessoas. Esta atitude limitou a participação destas pessoas na sociedade em geral, permitindo a participação apenas dos grupos formados por iguais.
\end{abstract}

É inegável o papel desempenhado pela mobilização de grupos populares e Organizações Não Governamentais (ONGs) na conquista da democracia. Muitas destas conquistas transformaram-se em direitos, como por exemplo, a Constituição Federal de 1988, onde foi garantido um passo a frente na defesa dos direitos humanos, em especial, nos direitos da pessoa com deficiência.

No artigo 18, inciso III, é explicitado o dever do Estado para com a oferta das escolas especializadas. No artigo 227, inciso II, é exigida a criação de programas de prevenção e atendimento especializado, bem como a integração social do adolescente portador de deficiência.

Da mesma forma que o direito à diferença representou uma conquista social, a garantia da educação como um direito de todos os cidadãos, se deu por meio de um complexo processo de evolução social. A esse respeito Horta (1998, p.6), afirma que:

[...] a vida, a liberdade, a propriedade privada e a segurança jurídica foram os primeiros direitos reconhecidos, proclamados e protegidos. A educação, por sua vez, apesar de sua grande importância, incorporou-se com grande atraso, aos seletos grupos dos direitos humanos, por meio de um processo lento, ambíguo e contraditório.

Para o mesmo autor, a Constituição de 1988 é incisiva quanto ao direito à educação e a obrigatoriedade escolar na legislação educacional brasileira, recuperando o conceito de educação, como direito público subjetivo, abandonado desde a década de 1930.

A Constituição citada acima inspira outros marcos legais, na direção da definição dos direitos sociais da cidadania, modificando o cenário das políticas publicas. Podem ser citados como principais: 
a) Estatuto da Criança e do Adolescente, Lei 8069/90, no art. 55 estabelece a obrigatoriedade dos pais matricularem seus filhos ou pupilos na rede regular de ensino. Tanto a matrícula quanto a frequência, são obrigatórias na rede oficial de ensino fundamental. No artigo 101, inciso III, incluem-se também as medidas de proteção a criança e ao adolescente, aplicáveis sempre que seus direitos forem ameaçados ou violados.

b) Lei de Diretrizes e Bases da Educação Nacional, Lei 9394/96 (BRASIL, 1996), estabelece:

Art. $4^{\circ} .-$ o dever do estado para com a educação escolar pública, será efetivado mediante a garantia de:

I - Ensino Fundamental, obrigatório e gratuito, inclusive os que a ele não tiveram acesso na idade própria;

II - progressiva extensão a obrigatoriedade e gratuidade ao ensino médio.

Art. $5^{\circ} .-0$ acesso ao ensino Fundamental é direito público subjetivo, podendo qualquer cidadão, grupo de cidadãos, associação comunitária, organização sindical, entidade de classe ou outra, legalmente constituída e, ainda, o Ministério Público, para exigi-lo.

Quanto a Lei de Diretrizes e Bases da Educação Nacional (BRASIL, 1996), a mesma trata das pessoas "portadoras de necessidades especiais", conforme aponta o texto, reservando um capitulo para a Educação Especial. No art. 58, o texto indica a educação de pessoas com deficiência "preferencialmente" no ensino regular.

Tal texto foi recebido com ressalvas pelos defensores da educação inclusiva. Porém, há que se considerar que mesmo não apresentando dispositivos no que diz respeito à estrutura e às políticas que assegurassem a inserção e permanência dos alunos com deficiência no ensino regular, os dispositivos desta lei, relacionados a flexibilização das formas organização curricular, ao acesso e a avaliação foram importantes. Além disso, num país como o Brasil, onde o "acesso a educação de pessoas com deficiência é escasso e revestido do caráter da concessão e do assistencialismo" (FERREIRA, 1998, p.1), essa lei representou um avanço em relação à legislação educacional até então existentes. 
Em 2001 formam instituídas as Diretrizes Nacionais para Educação Especial na Educação Básica (BRASIL, 2001). Este documento tem sua base na Declaração de Salamanca (UNESCO, 1994). A partir do mesmo foram instituídos os termos "educação inclusiva" e "necessidades educacionais especiais", passando a regulamentar a educação especial nos sistemas de ensino. A grande novidade em relação às diretrizes anteriores é que há um avanço no sentido que institui o "apoio pedagógico"5 para alunos com deficiência inseridos nas classes comuns.

Em setembro de 2007, a Secretaria de Educação Especial (SEESP) lança a versão preliminar da "Política Nacional de Educação Especial na Perspectiva da Educação Inclusiva” (BRASIL, 2008a). Em 2008, na versão final, o referido documento indica o atendimento especializado em Salas de Recursos e Centros Especializados de Referencias.

Cabe mencionar também o Decreto 6571 de 2008 (BRASIL, 2008b), que regulamenta o parágrafo único do Artigo 60 da Lei 9394/96 e prevê o apoio técnico e financeiro aos sistemas públicos de ensino nos estados e municípios que prestarem atendimento educacional especializado aos alunos com deficiência, transtorno global do desenvolvimento, superdotação e altas habilidades, matriculados na rede pública de ensino regular. O referido decreto regulamenta a distribuição dos recursos do Fundo Nacional de Desenvolvimento da Educação Básica (FUNDEB), para o "computo das matrículas da educação regular do ensino público que recebem ensino educacional especializado, sem prejuízo no computo dessas matriculas na Educação Básica regular." (art. $\left.9^{\circ}\right)$.

Assim, o aluno com deficiência atendido em escolas comuns contará em dobro para efeitos de cálculo do FUNDEB caso tenha atendimento educacional especializado no contraturno, com carga horária ampliada sem prejuízo de sua convivência com as demais crianças.

Desta forma, a política do MEC (Ministério da Educação e Cultura), a partir de 2005, tem adotado a posição de que a escolarização de alunos com deficiência deve darse diretamente no ensino comum. De acordo com esta proposta o papel das instituições

5 O artigo que trata do apoio pedagógico traz o seguinte texto: "serviços de apoio pedagógico especializado, realizado nas classes comuns, mediante: a) atuação colaborativa de professor especializado em educação especial, b) atuação de professores-intérpretes de linguagens e códigos aplicáveis; c) atuação de professores e outros profissionais itinerantes intra e interdisciplinares; d) atendimento especializado em Salas de Recursos e Centros Especializados de Referencias” (BRASIL, 2008b). 
especializadas fica restrito a proposta de atendimento especializado complementar ou suplementar.

Alguns autores - como Mantoan (2004b) e Figueiredo (2010a) - defendem a política para a educação inclusiva, de forma ampla, porém não sem os suportes necessários que garantam a aprendizagem. Não se trata, portanto, de garantir o acesso à escola e integrar o aluno, mas também assegurar os suportes necessários para que a aprendizagem se efetive.

Assim, considera-se que a perspectiva inclusiva representa uma nova forma de organizar a escola, de forma que todos possam beneficiar-se dela. Neste sentido, incluir pressupõe não só a aceitação e a tolerância com o diferente como um sujeito de direito, mas essencialmente pressupõe acreditar que todo indivíduo pode aprender, considerando ritmos e formas diferenciadas de aprendizagem.

\section{Inclusão: uma tentativa de conceituação}

Em termos conceituais, é preciso diferenciar os modelos de integração muito utilizado na década de 1990 e o atual modelo de inclusão, tratado nos textos legais. A principal diferença entre elas é que no modelo de integração, o principal responsável pela aprendizagem do aluno é o profissional especializado, mesmo que os programas de educação especial estivessem dentro das escolas, o ensino estava sob a responsabilidade do professor especialista, tornando-se como um espaço à parte no interior da instituição. No processo de inclusão este já não mais detém tal responsabilidade, mas sim o professor regente, já aos profissionais especializados cabe o apoio e suporte nas dificuldades encontradas em sala de aula, sejam elas pelo aluno, pelo professor ou até mesmo do gestor em articular sua pratica pedagógica.

Conforme esclarece Beyer (2006, p.73),

O projeto pedagógico inclusivo busca escapar desta dicotomia, ou seja, objetiva não produzir uma categorização "alunos com ou sem deficiência, com e sem distúrbios, com e sem necessidades especiais" (a adjetivação é ampla e flutuante, conforme os vários diagnósticos possíveis). Para tal abordagem educacional, não há dois grupos de alunos, porém apenas crianças e adolescentes que compõe a comunidade escolar e que apresentam necessidades variadas. 
Há que se considerar também que, vários autores têm recomendado cautela na instituição radical de uma política de inclusão escolar que não ofereça a opção de serviços especializados complementares. Entre eles pode-se citar: Lieberman (2003), Glat e Blanco (2007), Kassar, Oliveira e Silva (2007), Oliveira (2002), Pletsch (2010).

Não é possível ignorar que um dos graves problemas que representam entraves para a consolidação de uma política de educação inclusiva, é a descontinuidade dos serviços de suporte à inclusão. Estas ações têm estreita relação com interesses políticos e econômicos, uma vez que simplesmente integrar é considerado menos dispendioso. Contribuem para esta discussão, autores como: Ferreira e Ferreira (2004), Arruda, Kassar e Santos (2006) e Bueno (2002).

A Política Nacional de Educação Especial na Perspectiva da Educação Inclusiva reforça os direitos dos alunos com deficiências, conforme aponta:

\begin{abstract}
A Política Nacional de Educação Especial na Perspectiva da Educação Inclusiva tem como objetivo assegurar a inclusão escolar de alunos com deficiência, transtornos globais do desenvolvimento e altas habilidades/superdotação, orientando os sistemas de ensino para garantir: acesso ao ensino regular, com participação, aprendizagem e continuidade nos níveis mais elevados do ensino; transversalidade da modalidade de educação especial desde a educação infantil até a educação superior; oferta do atendimento educacional especializado e demais profissionais da educação para a inclusão; participação da família e da comunidade; acessibilidade arquitetônica, nos transportes, nos mobiliários, nas comunicações e informações e articulação inter setorial na implementação das políticas públicas. (BRASIL, 2008a, p.10).
\end{abstract}

Pode-se afirmar que muito se desenvolveu em nosso país em termo de legislação educativa voltada para a inclusão, porém, há muito que se avançar na quebra de barreiras, quer sejam, arquitetônicas ou pedagógicas. Conforme aponta Mantoan (2004a, p.24):

Há apoio legal suficiente para mudar, mas só temos tido, até agora, muitos entraves nesse sentido. Entre esses entraves estão: a resistência das instituições especializadas a mudanças de qualquer tipo; a neutralização do desafio à inclusão, por meio de políticas públicas que impedem que as escolas se mobilizem para rever suas práticas homogenizadoras e, em consequência, excludentes, o preconceito, o paternalismo em relação aos grupos socialmente fragilizados, como o das pessoas com deficiência [...], o corporativismo dos que se dedicam as pessoas com deficiência mental; a ignorância de muitos pais, a fragilidade de grande maioria deles diante do fenômeno da deficiência de seus filhos. 
O desafio das escolas que recebem alunos com deficiência é não permitir que ocorra apenas a integração deste aluno e sim a inclusão, acreditando-se que o aluno com deficiência é capaz de interagir e aprender, desde que os estímulos e variações metodológicas indiquem o respeito ao ritmo e singularidade de cada educando.

A mesma autora afirma que as escolas para serem avaliadas como escolas de qualidade são espaços educativos, espaços estes que privilegiam a construção de personalidades humanas autônomas e críticas.

Uma educação de qualidade é aquela que consegue formar o cidadão, além de oportunizar a descoberta de si e dos outros, por meio da troca de conhecimento, assim alcançando uma convivência social, saudável e humanizadora.

\begin{abstract}
A inclusão social, portanto é um processo que contribui para a construção de um novo tipo de sociedade através de transformações, pequenas e grandes, nos ambientes físicos (espaços internos e externos, equipamentos, aparelhos e utensílios, mobiliários e meios de transportes) e na mentalidade de todas as pessoas, portanto, também do próprio portador de necessidades especiais. (SASSAKI, 2002, p.41)
\end{abstract}

Assegurar ao aluno com deficiência oportunidade igual, não significa que se utilizará o mesmo procedimento metodológico, porém é necessário garantir que o mesmo se desenvolva como sujeito dentro de sua singularidade, compreendendo-se que cada pessoa desenvolve seu máximo conforme os estímulos que recebe.

Um olhar menos apurado identificaria um grande avanço no sentido de a escola constituir-se em um espaço de acolhimento ao diferente, porém observando mais atentamente percebe-se que os avanços ficam na maioria das vezes restritos às políticas educacionais expressa em ações norteadas por programas estabelecidos de forma burocrática. Estas ações, porém, não se tornam práticas normais do cotidiano escolar, ou seja, a escola não organiza seu cotidiano trabalhando com a diferença como uma ação normal, mas muitas vezes deixando claro o mal estar da presença da diferença no espaço escolar.

Sendo assim, a política da Educação Inclusiva, não está restrita a Leis, resoluções, diretrizes, programas e demais discussões de ordem estrutural. Embora estes fatores apresentem-se como essenciais no processo inclusivo, é necessário atentarmos para os aspectos de ordem pedagógica. 
Nesta perspectiva, o ensino tradicional seria substituído por uma pedagogia de atenção as diferenças. Neste enfoque a gestão pedagógica expressa por organização dos espaços e tempos escolares, da metodologia utilizada em sala de aula e no currículo adotado, necessita de uma transformação que contemple este novo paradigma.

Ainda quanto às políticas educacionais nos aspectos referentes à gestão e organização dos sistemas escolares, de similar relevância são os estudos de Carvalho (2007) que analisa a história da educação especial no Brasil e faz uma leitura dos marcos legais que fundamentam a política da educação inclusiva, bem como suas implicações no espaço escolar. A mesma autora traz, como dado essencial, a remoção de "barreiras na aprendizagem", deixando claro que as mesmas não existem porque as pessoas possuem deficiência, mas decorrem das expectativas do grupo em relação as suas potencialidades e das relações dos aprendizes com os recursos humanos e materiais, socialmente disponíveis, para atender as suas necessidades. Desta forma, as barreiras dependem do contexto no qual se inserem, da maneira como foram criadas e da forma como são muitas vezes eliminadas.

Considerando o novo paradigma vigente, os estudos de Figueiredo, apontam para uma mudança no interior da escola e na concepção pedagógica presente na instituição escolar. A mesma indica que para que uma escola chegue a todas as crianças em idade escolar requer mudanças. Para a autora, "a prática da inclusão implica no reconhecimento das diferenças dos alunos e na concepção de que a aprendizagem é construída em cooperação a partir das solicitações do meio, tendo o sujeito de conhecimento como um sujeito autonômo" (FIGUEIREDO, 2010b, p.66).

\section{A inclusão e a aprendizagem: elos possíveis?}

Assegurar o acesso à escola, embora tenha representado um grande desafio, é uma tarefa que pode ser cumprida por força da legislação vigente, porém garantir a aprendizagem requer uma transformação nas práticas escolares, tanto no que diz respeito ao currículo e às suas possibilidades de flexibilização, como também às práticas desenvolvidas pelos professores.

Quanto ao currículo, considera-se o mesmo como um dos agentes responsáveis pela inclusão e aprendizagem de todos os educandos. Para tanto, os autores estudados tratam do currículo em uma perspectiva critica. Pode-se citar Glat e Blanco (2007), Moreira e Silva (2006), Sacristán (2002), entre outros. 
Para Sacristán (2002, p.18),

Quanto mais as pessoas entrarem no sistema educacional e quanto mais tempo permanecerem nele, mais variações serão acumuladas em seu interior. A diferença existe. As práticas educativas (sejam de família, as da escola ou as de qualquer outro agente) deparam-se com a diversidade como um dado da realidade.

Assim, para que a escola se torne de fato, para todos, são necessárias transformações nas concepções de ensino que resultem em ações que privilegiem atenção às diferenças. A escola precisa ocupar-se com um currículo e práticas pedagógicas que tenham como ponto de partida o reconhecimento das diferentes situações sociais, cognitivas e culturais existentes na sala de aula. A concepção fundamentada sobre a aprendizagem no contexto das diferenças não está consolidada na escola, já que embora significativos avanços tenham acontecido na área de inclusão, esta instituição ainda se utiliza de práticas e mecanismos que reforçam a ideia da exclusão, da limitação, expressas em ações como reprovações e avaliações clinicas, como únicos recursos conhecidos para classificar os alunos.

A gestão escolar, as metodologias utilizadas pelos professores são fatores fundamentais na compreensão do fracasso escolar.

Nesta perspectiva, nos valemos da abordagem sociocultural de Vygotsky (1991). Para este autor, o aprendizado quando organizado de forma adequada resulta em desenvolvimento mental e movimenta vários processos deste desenvolvimento.

Para o mesmo autor é necessário considerar não só o nível de conhecimento conquistado, mas o nível de conhecimento potencial do sujeito, ou seja, a potencialidade para resolver situações com a ajuda de um mediador.

A proposta da inclusão de pessoas com deficiência no mesmo sistema escolar que os alunos ditos normais reforça a ideia de que o ser humano não é só um ser biológico, mas social, que aprende em contato com seu meio.

Quando o ser humano nasce possui apenas as características biológicas comuns a sua espécie que podem ser consideradas a base de seu processo de desenvolvimento. Mas este processo só vai concretizar-se na relação com o outro.

Desde o nascimento o sujeito ingressa, progressivamente, em um mundo de relações que são mediadas pelas significações, valores e atitudes de sua cultura. A essência da teoria de Vygotsky (1991) é, portanto, o reconhecimento do sujeito 
biológico, porém considerando como componente essencial às determinações sociais, concluindo que a gênese da constituição do ser humano é histórico cultural.

Alguns pressupostos devem ser destacados como fundamentais no sentido de uma mudança sobre os sujeitos com deficiência tanto na sociedade como no espaço escolar. Neste sentido, a matriz histórico-cultural nos traz contribuições na medida em que compreendemos o sujeito como se originando nas relações concretamente vividas e se constituindo a partir delas, entendendo cultura de maneira ampla como produto da vida social e a atividade social do ser humano.

É importante compreender o conceito de relação social na perspectiva dos sujeitos com deficiência, ou seja, aquela na qual o sujeito está "junto ao meio", não estando fora ou sendo somente influenciado pelo mesmo.

Desta forma, na presença de uma deficiência fica evidente que o processo de desenvolvimento não se dá naturalmente, mas é construído a partir de condições concretas de vida, que não estão pré-definidas no sujeito e nem na família ou grupo cultural no qual a pessoa está inserida, mas se constroem nas relações sociais.

Pode-se afirmar, portanto, que é a partir das significações, atribuídas pelo outro, no primeiro momento e mais tarde internalizadas pela própria pessoa, que cada um se constitui de maneira singular e constrói o seu conhecimento.

Importante destacar aqui o caráter dialético assumido rumo à amplitude de conceitos que subsidiam as práticas voltadas ao meio social, num movimento que articula o desenvolvimento biológico do individuo e o meio no qual se desenvolvem. Tendo-se claro que o que é mais importante no processo da aprendizagem não são as características biológicas individuais, mas as suas relações sociais nos diferentes momentos históricos.

Desta forma não é mais possível aceitar que os sujeitos sejam reduzidos a algumas peculiaridades no seu processo de desenvolvimento, mas sim considerá-lo, ainda que respeitando-se a sua singularidade e características orgânicas, como um sujeito capaz de construir conhecimento e desta forma definir sua maneira de ser e estar no mundo.

Para Carneiro (2007), esta não é uma concepção hegemônica do desenvolvimento humano. Observando as práticas escolares, encontramos a valorização de um sujeito com desenvolvimento já efetivado, desconsiderando as funções que estão em processo de maturação. O produto sempre sendo mais valorizado do que o processo, o aluno é avaliado pelas respostas que dá individualmente. Nesta perspectiva de 
avaliação é considerado apenas o nível de desenvolvimento efetivo, isto é, apenas aquelas funções que já estão desenvolvidas na criança e que nos permitem que ela resolva determinados problemas de forma independente. Não consideram que as interações promovem processos de aprendizagem, impulsionando o desenvolvimento.

De acordo com Vygotsky (1991), o ensino não deve apoiar-se no que já foi alcançado pela criança, mas nos processos em desenvolvimento potencial que a mesma apresenta, porém com conhecimentos ainda não consolidados. Trata-se de mudança de foco, concentrando-se nas possibilidades da criança e não em suas dificuldades, mesmo quando se trata de crianças com deficiência.

Para o mesmo autor é da vida social da criança, das oportunidades de acesso aos signos culturais, nos quais encontram o material para construir funções psicológicas superiores que lhe permitem estar inseridas nas práticas sociais de seu grupo cultural. É importante, portanto, conhecer como se desenvolve um sujeito com deficiência e como este constrói seu conhecimento, tornando-se menos importante a falta, a carência, o déficit, mas valorizando o potencial que apresenta para aprender e as construções já realizadas. Não se trata de negar o déficit como uma condição apresentada pelo sujeito com algum comprometimento orgânico, mas de reconhecer que existe uma condição que não é dada inicialmente, mas que vai se construindo na medida em que se possibilitam condições de desenvolvimento de acordo com as suas peculiaridades.

Nesta perspectiva, considera-se o quanto se oferece a estes sujeitos com deficiência, ambientes e práticas simplificadas, adaptadas a condição inicial apresentada por cada um deles para a construção do conhecimento.

Como afirmam Vygotsky, Luria e Leóntiev (1988, p.114):

Um ensino orientado até uma etapa de desenvolvimento já realizado é ineficaz do ponto de vista do desenvolvimento geral da criança, não é capaz de dirigir o processo de desenvolvimento, mas vai atrás dele. A teoria do âmbito de desenvolvimento potencial (Zona de Desenvolvimento Proximal) origina uma formula que contradiz exatamente a orientação tradicional: o único bom ensino é o que se adianta ao desenvolvimento.

Mais especificamente, sobre o ensino de crianças com deficiência mental (VYGOTSKY, 1991, p.100).

[...] o sistema de ensino baseado somente no concreto - um sistema que eliminado ensino tudo aquilo que está associado ao pensamento abstrato falha em ajudar as crianças retardadas a superarem suas 
deficiências inatas, além de reforçar essas deficiências, acostumando as crianças exclusivamente ao pensamento concreto e suprimindo, assim os rudimentos de qualquer pensamento abstrato que essas crianças ainda possam ter. Precisamente porque as crianças retardadas, quando deixadas a si mesmas, nunca atingirão formas bem elaboradas de pensamento abstrato, é que a escola deveria fazer todo esforço para empurrá-las nessa direção, para resolver nelas o que esta intrinsecamente faltando no seu próprio desenvolvimento.

Assim, considera-se que todo ser humano pode aprender, ainda que com condições físicas, mentais, sensoriais, neurológicas ou emocionais significativamente diferentes, poderá desenvolver suas funções superiores.

\section{Articulações finais}

É possível, afirmar, portanto que o desenvolvimento humano se dá no entrelaçamento de aspectos biológicos e culturais.

Neste sentido, o processo das funções psíquicas superiores está intrinsecamente relacionado ao meio social e cultural e a interação com outras pessoas, na medida em que o uso dos signos é coletivo e tem seus significados compartilhados nessas interações.

Essa teia só é possível se o mediador, no caso o professor, reconhecer o aluno com deficiência como um sujeito capaz de aprender.

Também é importante que a escola como um todo reconheça que o princípio da inclusão não pode ser compreendido somente por alguns. Esse princípio deve ser o norteador de toda prática escolar, num processo constante de reflexão, identificando elementos cristalizados na prática cotidiana que precisam ser transformados. 


\section{INCLUSION OF STUDENTS WITH DISABILITIES IN THE EARLY YEARS OF ELEMENTARY EDUCATION SOME CONSIDERATIONS}

ABSTRACT: This paper aims to discuss, even if briefly, the inclusion in the regular school of the students with disabilities. For this, we sought based reasoning, the analysis of legal documents dealing with the public policy of the school inclusion of students with disabilities in Brazil, as well as authors who deal with this theme. The text also deals with the issue of learning and school failure, considering the school routine, the style of school management and pedagogical practices present in public schools, as relevant categories in the process of school inclusion of students with disabilities.

KEYWORDS: Inclusion. Public policy. Students with disabilities.

\section{REFERÊNCIAS}

ARRUDA, E.E. de; KASSAR, M. de C.; SANTOS, M. M. Educação Especial: o custo do atendimento de uma pessoas com necessidades especiais em instituições públicas, estatal e não estatal, em MS, 2004. In: NERES, C.C.; LANCILLOTTI, S. S. P. (Org.). Educação especial em foco: questões contemporâneas. Campo Grande: Uniderp, 2006. (Educação em Perspectiva). p.89-116.

BATISTA, C.A.M. Políticas Sociais, Organizações da Sociedade Civil e o Processo de Inclusão das Pessoas com Deficiência no Brasil. In: TEODÓSIO, A. S. S. et al. Gestão Inclusiva: primeiro, segundo e terceiro setor. Belo Horizonte: Armazém de Ideias, 2003. p.9-27.

BEYER, H.O. Da integração escolar a educação inclusiva: implicações pedagógicas. In: BAPTISTA, C. R. (Org.). Inclusão e escolarização: múltiplas perspectivas. Porto Alegre: Mediação, 2006. p.73-82.

BRASIL. Ministério da Educação. Política Nacional de Educação Especial na Perspectiva da Educação Inclusiva. Brasília: MEC/SEESP, 2008a.

Decreto $\mathrm{n}^{\circ}$ 6.571, de 17 de setembro de 2008. Dispõe sobre o atendimento educacional especializado, regulamenta o parágrafo único do art. 60 da Lei no 9.394, de 20 de dezembro de 1996, e acrescenta dispositivo ao Decreto no 6.253, de 13 de novembro de 2007. Diário Oficial. Brasília, 2008b. Disponível em: <http://www.planalto.gov.br/ccivil_03/_ato2007-2010/2008/Decreto/D6571.htm>. Acesso em: 1 mai. 2015.

. Ministério da Educação. Secretaria de Educação Especial. Diretrizes nacionais para a educação especial na educação básica. Brasília: MEC/SEESP, 2001.

. Lei $\mathrm{n}^{\circ}$ 9.394, de 20 de dezembro de 1996. Estabelece as diretrizes e bases da educação nacional. Diário Oficial. Brasília, 1996. Disponível em: <http://www.planalto.gov.br/ccivil_03/leis/19394.htm>. Acesso em: 1 mai. 2015. 
Lei no 4.024, de 20 de dezembro de 1961. Fixa as Diretrizes e Bases da Educação Nacional. Diário Oficial. Brasília, 1961. Disponível em: <http://www.planalto.gov.br/ccivil_03/leis/14024.htm>. Acesso em: 1 mai. 2015.

BUENO, J. G. S. A Educação Especial nas universidades brasileiras. Brasília: Ministério da Educação, Secretaria de Educação Especial, 2002.

CARNEIRO, M. S. C. Deficiência mental como produção social: uma discussão a partir de historia de vida de adultos com Síndrome de Down. 193f. 2007. Dissertação (Doutorado em Educação) - Universidade Federal do Rio Grande do Sul, Porto Alegre, 2007.

CARVALHO, R. E. Removendo barreiras para a aprendizagem. Porto Alegre: Mediação, 2007.

CHARLOT, B. Formação de Professores: a pesquisa e a política educacional. In: PIMENTA, S. G.; GHEDIN, E. (Org.). Professor Reflexivo no Brasil: gênese e crítica de um conceito. São Paulo: Cortez, 2005. p.89-108.

CONFERÊNCIA MUNDIAL DE EDUCAÇÃO PARA TODOS [Wcefa]. Declaração mundial sobre educação para todos e plano de ação para satisfazer as aprendizagens básicas de aprendizagem. Jomtien, Tailândia, 1990.

FERREIRA, J. R. A nova LDB e as necessidades educativas especiais. Caderno Cedes, Campinas, v.19, n.46, p.7-15, 1998.

FERREIRA, M. C. C.; FERREIRA, J. R. Sobre inclusão, políticas públicas e práticas pedagógicas. In: GÓES, M.C.R; LAPLANE, A. L. F. (Org.). Políticas e práticas de educação inclusiva. São Paulo: Autores Associados, 2004. p.21-48.

FIGUEIREDO, R. V. (Org.). Escola, diferença e inclusão. Fortaleza: Ed. da UFC, 2010a.

Novas luzes sobre a inclusão escola. Fortaleza: Ed. da UFC, 2010 b.

GLAT, R.; BLANCO, L. de M. V. Educação Especial no contexto de uma Educação Inclusiva. In: GLAT, R. (Org.). Educação Inclusiva: cultura e cotidiano escolar. Rio de Janeiro: Sete Letras, 2007. (Coleção Questões atuais em Educação Especial, v. VI). p.15-35.

HORTA, J. S. Direito à Educação e Obrigatoriedade Escolar. Cadernos de Pesquisa Fundação Carlos Chagas, São Paulo, n.104, jul. 1998.

KASSAR, M. de C.M.; OLIVEIRA, A.D.; SILVA, G.A.M. Inclusão em escolas municipais: análise inicial de um caso. Revista Educação, Santa Maria, v.32, n.2, p.397-410, 2007.

LIEBERMAN, L.M. Preservar a educação especial... Para aqueles que dela necessitam. In: CORREIA, L.M. Educação especial e inclusão: quem disser que uma sobrevive sem a outra não está em perfeito juízo. Porto: Porto Editora, 2003. p.89-107. 
LISPECTOR, C. A descoberta do mundo. São Paulo: Nova Fronteira, 1984.

MANTOAN, M. T. E. Caminhos pedagógicos da educação inclusiva. In: GAIO, R.; MENEGHETTI, R.K. (Org.). Caminhos pedagógicos da educação especial. Petrópolis: Vozes, 2004a. p.79-84.

O direito de ser, sendo diferente, na escola. In: Inclusão: intenção e

realidade. Marília: Fundepe, 2004b. p.113-143.

MOREIRA, A. F.; SILVA, T.T. da (Org.). Currículo, culltura e sociedade. 9.ed. São Paulo: Cortez, 2006.

OLIVEIRA, A.A.S. Representações sociais sobre educação especial e deficiência: o ponto de vista de alunos deficientes e professores especializados. $2002.318 \mathrm{f}$. Tese (Doutorado em Educação) - Universidade Estadual Paulista, Marília, 2002.

ORGANIZAÇÃO DAS NAÇÕES UNIDAS PARA A EDUCAÇÃO, A CIÊNCIA E A CULTURA [UNESCO]. Declaração de Salamanca e linha de ação sobre necessidades educativas especiais. Brasília: CORDE, 1994.

PARO, V. H. Reprovação Escolar: renúncia à educação. São Paulo: Xamã, 2001.

PLETSCH, M. D. Repensando a inclusão escolar: diretrizes políticas, práticas curriculares e deficiência intelectual. Rio de Janeiro: NAU/EDUR, 2010.

SACRISTÁN, J. G. et al. Atenção à diversidade. Porto Alegre: ArtMed, 2002.

SASSAKI, R.K. Inclusão: construindo uma sociedade para todos. Rio de Janeiro: WVA, 2002.

VIGOTSKY, L. S.; LURIA, A. R.; LEÓNTIEV, A. N. Linguagem, desenvolvimento e aprendizagem. São Paulo: Ícone, 1988.

VYGOTSKY, L. S. A formação social da mente. São Paulo: Martins Fontes, 1991. 